\title{
Hormone replacement therapy and risks of oesophageal and gastric adenocarcinomas
}

\author{
M Lindblad", , LA García Rodríguez ${ }^{2}$, E Chandanos' and J Lagergren ${ }^{1,3}$ \\ 'Unit of Oesophageal and Gastric Research, Department of Molecular Medicine and Surgery, Karolinska Institutet, Stockholm, Sweden; ${ }^{2}$ Centro Español \\ de Investigación Farmacoepidemiológica, Madrid, Spain; ${ }^{3}$ Department of Medical Epidemiology and Biostatistics, Karolinska Institutet, Stockholm, Sweden
}

Oesophageal and gastric adenocarcinoma share an unexplained male predominance, which would be explained by the hypothesis that oestrogens are protective in this respect. We carried out a nested case-control study of hormone replacement therapy (HRT) among 299 women with oesophageal cancer, 313 with gastric cancer, and 3191 randomly selected control women, frequency matched by age and calendar year in the General Practitioners Research Database in the United Kingdom. Data were adjusted for age, calendar year, tobacco smoking, alcohol consumption, body mass index, hysterectomy, and upper gastrointestinal disorders Among I 619563 person-years of follow-up, more than 50\% reduced risk of gastric adenocarcinoma was found among users of HRT compared to nonusers (odds ratio (OR), 0.48, 95\% confidence interval (Cl) 0.29-0.79). This inverse association appeared to be stronger for gastric noncardia (OR $0.34,95 \% \mathrm{Cl} 0.14-0.78$ ) and weaker for gastric cardia tumours (OR 0.68, 95\% Cl 0.23-2.01). There was no association between HRT and oesophageal adenocarcinoma (OR I.17, 95\% Cl 0.4I-3.32). British Journal of Cancer (2006) 94, 136-141. doi:I0.1038/sj.bjc.6602906 www.bjcancer.com Published online 13 December 2005

(c) 2006 Cancer Research UK

Keywords: oestrogen; hormone replacement therapy; gastric cancer; oesophageal adenocarcinoma

The male predominance is a striking and unexplained feature of oesophageal and gastric adenocarcinomas, the sex ratio being $6: 1$ in both oesophageal and gastric cardia adenocarcinoma, and 2:1 in gastric noncardia adenocarcinoma (Corley and Buffler, 2001; Parkin, 2001). The $3: 1$ male predominance in oesophageal squamous-cell carcinoma is explicable by sex differences in the prevalence of the main risk factors, that is, use of tobacco and alcohol (Muir and McKinney, 1992; Gammon et al, 1997; Lagergren et al, 2000). However, no corresponding sex difference in the established risk factors for oesophageal or gastric adenocarcinoma can explain their male predominance (EUROGAST, 1993; Moller et al, 1994; Lagergren et al, 1999a, b; Kelley and Duggan, 2003; Crew and Neugut, 2004). It has been hypothesised that female sex hormones, mainly oestrogens, may explain or contribute to these sex differences. In two prostate cancer cohort studies, of men heavily exposed to oestrogens, there was no reduction in the risk of oesophageal adenocarcinoma (Lagergren and Nyren, 1998), although a decreased risk of gastric adenocarcinoma has been reported (Lindblad et al, 2004). An increased male-to-female ratio in gastric adenocarcinoma has been claimed as corresponding to a 10- to 15-year delay among females compared with males, possibly due to a protective effect of female sex hormones (Sipponen and Correa, 2002). Studies on menstrual and reproductive factors have suggested associations with the risk of gastric adenocarcinoma

*Correspondence: Dr M Lindblad, Department of Surgery P9: 03, Karolinska University Hospital, Solna, Stockholm SE-17I 76, Sweden; E-mail: mats.lindblad@karolinska.se

Received 3 August 2005; revised 14 November 2005; accepted 16 November 2005; published online 13 December 2005
(Miller et al, 1980; Plesko et al, 1985; La Vecchia et al, 1994; Palli et al, 1994; Heuch and Kvale, 2000; Inoue et al, 2002; Kaneko et al, 2003). Based on the hypothesis that sex hormones may be involved in the aetiology of oesophageal or gastric adenocarcinoma, we investigated whether hormone replacement therapy (HRT) protects women against either of these tumours.

\section{MATERIALS AND METHODS}

\section{General practice research database}

We collected our data from the General Practice Research Database (GPRD) in the United Kingdom (UK). This database has been described in detail elsewhere (Garcia Rodriguez and Perez Gutthann, 1998). The large number of person-years of follow-up makes the GPRD a valuable resource even for the study of rare diseases, and we have previously used this database to study risk factors for oesophageal and gastric cancer (Lindblad et al, 2005). The computerised information in the GPRD includes prospective recordings of diagnoses, prescriptions of drugs, demographics, details of every general practitioner's (GPs) consultation, results from laboratory tests, hospital letters, and a free text section. Diagnoses are coded by a modification of the Oxford Medical Information System (OXMIS) and the Read classification systems. A drug dictionary based on data from the Prescription Pricing Authority is used to code drugs. All prescriptions are automatically entered into the GPRD since they are directly generated from the participating GP's computer, thus ensuring a complete recording. Validation studies have shown that the GPRD data are of high quality (Jick et al, 2003). More than $90 \%$ of all referrals are entered 
into the GPs computer with the specialist's diagnosis carefully coded (Jick et al, 1991).

\section{Study cohort}

During the study period, January 1994 through December 2001, we identified all women in the GPRD aged between 50 and 84 years. To be included in the study cohort, the person had to have been enrolled with the GP for at least 2 years, and with at least 1 year of computerised prescription history. Any person with a cancer history recorded in the GPRD before start date was excluded. All women in the study cohort were followed up until any of the following events occurred: (1) detection of an oesophageal or gastric cancer, (2) detection of any other cancer, (3) age of 85 years, (4) death, or (5) end of study period (31 December 2001), whichever occurred first.

\section{Identification of study participants}

Within the study period, a computerised search identified 705 female subjects with a diagnosis code of oesophageal or gastric cancer. To verify and further classify the tumours, all computerised patient profiles of these patients were manually reviewed by one investigator (ML) who was kept blinded to the exposure data. Moreover, GPs sent additional information regarding case patients identified by the computer $(N=346)$. All available information about the tumour site and histology, as well as paper-based information (e.g. operation and pathology reports and letters from specialists) were reviewed. Patients were excluded if: (1) the tumour was benign, (2) the origin of a cancer was unknown, (3) the tumour was a metastasis, (4) the patient had another, concurrent cancer, (5) the cancer was diagnosed before the start date, or (6) the histological type was not adenocarcinoma or squamous-cell carcinoma. The index date among our case patients was set to be the date when the tumour was first recorded or when the manual review revealed an earlier date of diagnosis. All persons received a random date within the study period, and if it was within that individual's eligible person-time, she was marked as an eligible control subject. Thereafter, we randomly selected control subjects and their random dates were set as index dates. The control participants were frequency matched on age (within 1 year) and same calendar year.

\section{Drug exposure definition}

Only drug exposure preceding the index date was considered in the study. The information recorded in the GPRD, drug medications and HRT included, could date back to the late 1980s when the database was initiated. HRT included oral oestrogens, transdermal oestradiol, oestradiol implants, and tibolone, and use was classified as nonuse or ever use when there was no or any recorded use in the database, respectively. Ever users were further categorised as current users if use of HRT had been within the year prior to index date, and past users if the most recent use was before that. Duration of HRT use was calculated summing the periods of consecutive prescriptions among ever users, grouped into two levels: less than 3 years of treatment duration and 3 years and more.

\section{Statistical analyses}

Unconditional logistic regression was conducted to calculate odds ratios (ORs) with 95\% confidence intervals (CIs). In multivariable analyses, all estimates of risk were adjusted for the following potential confounding factors: age (in 10-year intervals), calendar year, tobacco smoking (categorised in four groups: nonsmoker, current smoker, ex-smoker, or unknown), alcohol consumption (categorised in five groups: $0-2,3-15,16-34,>34 \mathrm{Uday}^{-1}$, or unknown, where one unit corresponded to $10 \mathrm{ml}$ or $7.9 \mathrm{~g}$ of pure ethanol), body mass index (BMI) (categorised in five groups: $<20$, $20-24.9,25-29.9,>30 \mathrm{~kg} \mathrm{~m}^{-2}$, or unknown), hysterectomy (categorised in two groups: yes or no), and upper gastrointestinal disorders (categorised in two groups: never or ever). Upper gastrointestinal disorders were defined as any recording in the GPRD of gastrooesophageal reflux disease, peptic ulcer, dyspepsia, or prescription of acid-suppressing drugs (proton-pump inhibitors or $\mathrm{H}_{2}$-receptor blockers).

\section{Ethics}

The Scientific and Ethical Advisory Group (SEAG) in the UK approved the Study.

\section{RESULTS}

\section{Study participants}

Among 1619563 person-years of follow-up, the computerised search identified 705 women with oesophageal or gastric cancer. After excluding 93 during the manual review for any of the previously stated reasons, 299 were classified as oesophageal cancer and 313 as gastric cancer. The crude incidence rate was 18.5/100000 person-years for oesophageal cancer and $19.3 / 100000$ person-years for gastric cancer. Oesophageal tumours were further classified by histological type, and gastric tumours into gastric subsite as presented in Table 1. Some basic characteristics of the study participants are shown in Table 1. The median ages among patients with oesophageal cancer, gastric cancer, and control subjects were 74,73 , and 74 years, respectively, and no striking differences were noted between the cancer subgroups. In the youngest age group (50-59 years), gastric cardia were over-represented and oesophageal adenocarcinomas were under-represented. Never smokers were more frequent among control participants than among all cancer subgroups. The prevalence of obesity $\left(\mathrm{BMI}>30 \mathrm{~kg} \mathrm{~m}^{-2}\right)$ and of upper gastrointestinal disorders was higher in oesophageal and gastric cardia adenocarcinomas than among controls, oesophageal squamous-cell carcinomas, and gastric noncardia adenocarcinomas. The median time of data collection between first drug prescription and index date was similar between cases (2323 days) and controls (2272 days).

\section{HRT and oesophageal cancer}

HRT was not associated with the risk of oesophageal cancer of any histological type (OR $0.84,95 \%$ CI $0.51-1.38$ ) as shown in Table 2. Multivariable analysis revealed an OR of 1.17 (95\% CI $0.41-3.32)$ for oesophageal adenocarcinoma among ever users of HRT compared to nonusers. The corresponding OR for oesophageal squamous-cell carcinoma was 0.93 (95\% CI $0.40-2.16)$. Adjustment for all covariates listed in the Materials and Methods section did not materially change the age-adjusted risk estimates, indicating lack of strong confounding by these covariates (Table 2). The limited numbers of exposed cases and controls prohibited valid analyses of duration and recency of HRT use, but the point estimates were constant over treatment duration, while lower estimates were found among current users (OR 0.68).

\section{HRT and gastric cancer}

Ever use of HRT was associated with a reduced risk of gastric adenocarcinoma by $52 \%$ compared to nonusers (OR $0.48,95 \%$ CI 0.29-0.79) (Table 3). The corresponding analysis restricted to gastric cardia adenocarcinoma indicated a 32\% reduced risk without statistical significance (OR $0.68,95 \%$ CI $0.23-2.01$ ). The $66 \%$ reduced risk of gastric noncardia adenocarcinoma was 
Table I Selected basic characteristics among case patients and control participants

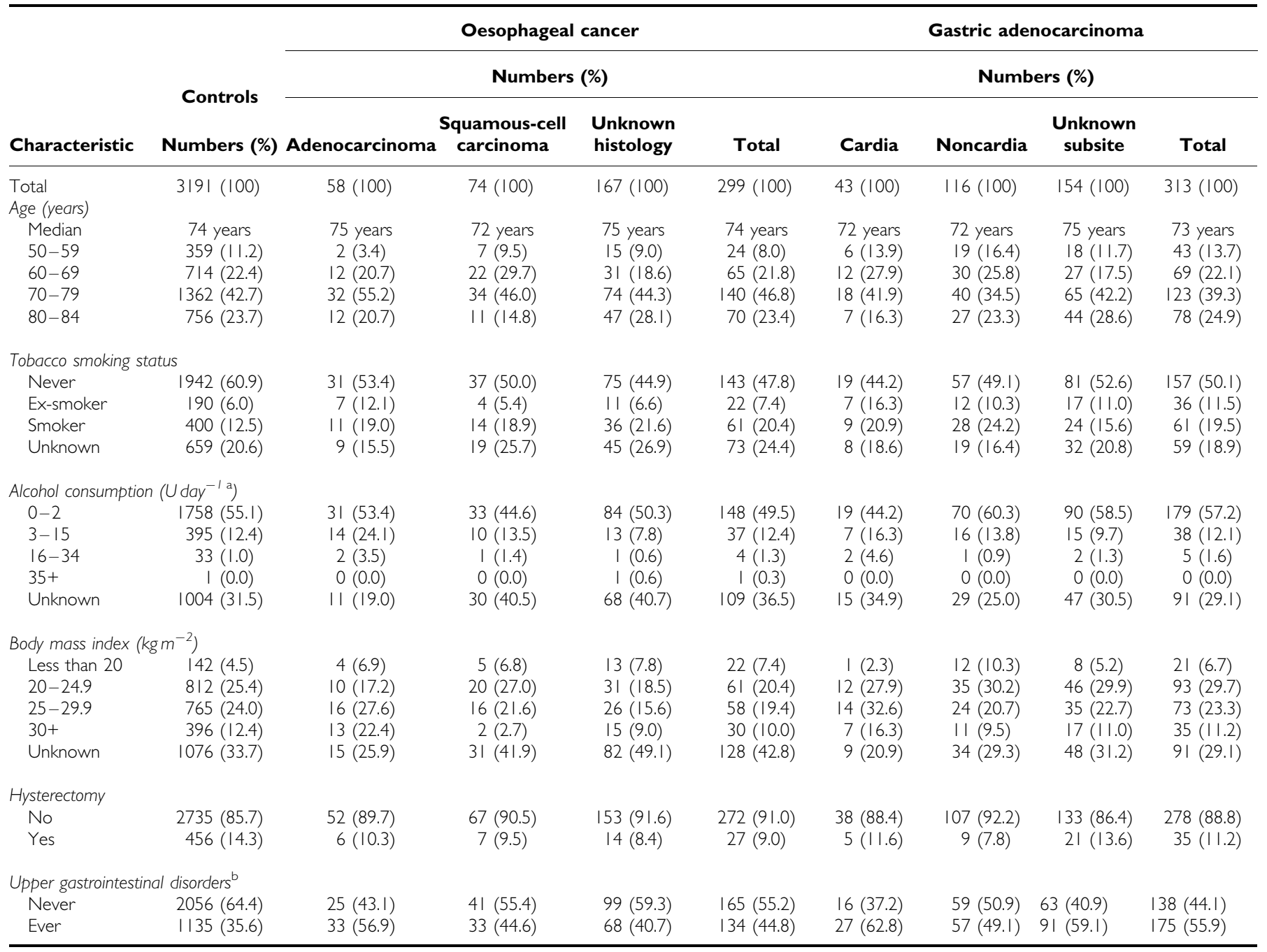

${ }^{a}$ One unit of alcohol corresponds to $10 \mathrm{ml}$ or $7.9 \mathrm{~g}$ of pure ethanol. b Upper gastrointestinal disorders were defined as any recording in the GPRD of gastrooesophageal reflux disease, peptic ulcer, dyspepsia, or prescription of acid-suppressing drugs (proton-pump inhibitors or $\mathrm{H}_{2}$-receptor blockers).

Table 2 Odds ratios (ORs) with 95\% confidence intervals (Cls) on the association between use of hormone replacement therapy (HRT) and risk of oesophageal cancer

\begin{tabular}{|c|c|c|c|c|c|c|c|c|c|}
\hline \multirow[b]{2}{*}{ Exposure } & \multirow{2}{*}{$\begin{array}{c}\text { Control } \\
\text { subjects } \\
N(\%)\end{array}$} & \multicolumn{2}{|c|}{$\begin{array}{c}\text { Oesophageal } \\
\text { adenocarcinoma }\end{array}$} & \multicolumn{2}{|c|}{$\begin{array}{l}\text { Oesophageal squamous-cell } \\
\text { carcinoma }\end{array}$} & \multicolumn{2}{|c|}{$\begin{array}{l}\text { Oesophageal cancer of } \\
\text { unknown histology }\end{array}$} & \multicolumn{2}{|c|}{ Total oesophageal cancer } \\
\hline & & $N(\%)$ & OR $(95 \% \mathrm{Cl})$ & $N(\%)$ & OR (95\% Cl) & $N(\%)$ & OR $(95 \% \mathrm{Cl})$ & $N(\%)$ & OR $(95 \% \mathrm{Cl})$ \\
\hline \multicolumn{10}{|l|}{ HRT } \\
\hline $\begin{array}{l}\text { Never } \\
\text { Ever }\end{array}$ & $\begin{array}{r}2846(89.2) \\
345(10.8)\end{array}$ & $\begin{aligned} 53 & (91.4) \\
5 & (8.6)\end{aligned}$ & $\begin{array}{l}1.00 \text { (reference) }^{\mathrm{a}} \\
1.27(0.46-3.48)^{\mathrm{a}} \\
1.17(0.41-3.32)^{\mathrm{b}}\end{array}$ & $\begin{array}{r}66(89.2) \\
8(10.8)\end{array}$ & $\begin{array}{l}1.00 \text { (reference) } \\
0.94(0.42-2.15)^{\mathrm{a}} \\
0.93(0.40-2.16)^{\mathrm{b}}\end{array}$ & $\begin{array}{l}\text { I57 (94.0) } \\
10(6.0)\end{array}$ & $\begin{array}{l}1.00 \text { (reference) }^{\mathrm{a}} \\
0.56(0.28-1.15)^{\mathrm{a}} \\
0.65(0.31-1.37)^{\mathrm{b}}\end{array}$ & $\begin{array}{c}276(92.3) \\
23(7.7)\end{array}$ & $\begin{array}{l}\text { I.00 (reference) } \\
0.78(0.48-1.26)^{\mathrm{a}} \\
0.84(0.5 \mathrm{I}-1.38)^{\mathrm{b}}\end{array}$ \\
\hline
\end{tabular}

${ }^{\mathrm{a}}$ ORs adjusted only for age. ${ }^{\mathrm{b}}$ ORs adjusted for age, calendar year, tobacco smoking, alcohol consumption, body mass index, hysterectomy, and upper gastrointestinal disorders.

statistically significantly (OR $0.34,95 \%$ CI $0.14-0.78$ ). Stratified analysis by age groups and tobacco smoking status revealed a more pronounced inverse association in older compared to younger women, while no difference in risk was found between smokers and nonsmokers (Table 4). For HRT use of less than 3 years, OR was 0.34 (95\% CI $0.17-0.67)$ of gastric cancer, while for at least 3 years it was $0.72(95 \%$ CI $0.38-1.38)$. Current users of HRT were associated with a reduced risk of gastric cancer (OR
$0.56,95 \%$ CI $0.33-0.96$ ) as well as past users (OR 0.25, 95\% CI $0.09-0.70)$.

\section{DISCUSSION}

This study indicates that use of HRT was associated with a markedly reduced risk of gastric adenocarcinoma, possibly greater 
Table 3 Odds ratios (ORs) with 95\% confidence intervals (Cls) on the association between use of hormone replacement therapy (HRT) and risk of gastric adenocarcinoma

\begin{tabular}{|c|c|c|c|c|c|c|c|c|c|}
\hline \multirow[b]{2}{*}{ Exposure } & \multirow{2}{*}{$\begin{array}{c}\text { Control } \\
\text { subjects } \\
N(\%)\end{array}$} & \multicolumn{2}{|c|}{$\begin{array}{c}\text { Gastric cardia } \\
\text { adenocarcinoma }\end{array}$} & \multicolumn{2}{|c|}{$\begin{array}{l}\text { Gastric noncardia } \\
\text { adenocarcinoma }\end{array}$} & \multicolumn{2}{|c|}{$\begin{array}{c}\text { Unknown subsite of gastric } \\
\text { adenocarcinoma }\end{array}$} & \multicolumn{2}{|c|}{$\begin{array}{c}\text { Total gastric } \\
\text { adenocarcinoma }\end{array}$} \\
\hline & & $N(\%)$ & OR $(95 \% \mathrm{Cl})$ & $N(\%)$ & OR $(95 \% \mathrm{Cl})$ & $N(\%)$ & OR (95\% Cl) & $N(\%)$ & OR $(95 \% \mathrm{CI})$ \\
\hline \multicolumn{10}{|l|}{ HRT } \\
\hline Never & $2846(89.2)$ & $38(88.4)$ & I.00 (reference) & $109(94.0)$ & 1.00 (reference) & | 43 (92.9) & 1.00 (reference) & $290(92.6)$ & 1.00 (reference) \\
\hline Ever & $345(10.8)$ & $5(11.6)$ & $0.85(0.30-2.44)^{\mathrm{a}}$ & & $0.34(0.15-0.77)^{\mathrm{a}}$ & & $0.61(0.30-1.21)^{\mathrm{a}}$ & & $0.5 \mathrm{I}(0.32-0.83)^{\mathrm{a}}$ \\
\hline & & & $0.68(0.23-2.01)^{b}$ & $7(6.0)$ & $0.34(0.14-0.78)^{b}$ & $11(7.1)$ & $0.55(0.27-1.12)^{b}$ & $23(7.4)$ & $0.48(0.29-0.79)^{b}$ \\
\hline
\end{tabular}

${ }^{\mathrm{a} O R s}$ adjusted for age. ${ }^{\mathrm{b} O R s}$ adjusted for age, calendar year, tobacco smoking, alcohol consumption, body mass index, hysterectomy, and upper gastrointestinal disorders.

Table 4 Odds ratios (ORs) with 95\% confidence interval (Cl) on the association between use of hormone replacement therapy and gastric adenocarcinoma stratified by age and tobacco smoking categories

\begin{tabular}{lc}
\hline Stratified category & $\begin{array}{c}\text { Gastric adenocarcinoma } \\
\text { OR } \mathbf{( 9 5 \% ~} \mathbf{~ C l})^{\mathbf{a}}\end{array}$ \\
\hline Age (years) & \\
$50-59$ & $0.53(0.25-1.13)$ \\
(Number of exposed cases/controls) & $(16 / 173)$ \\
$60+$ & $0.38(0.18-0.84)$ \\
(Number of exposed cases/controls) & $(7 / 172)$ \\
Tobacco smoking status & OR $(95 \% \mathrm{Cl})$ \\
Never & $0.53(0.26-1.08)$ \\
(Number of exposed cases/controls) & $(11 / 214)$ \\
Ever & $0.52(0.24-1.12)$ \\
(Number of exposed cases/controls) & $(13 / 107)$ \\
\hline
\end{tabular}

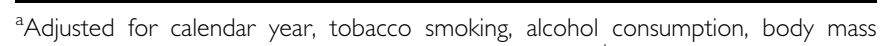
index, hysterectomy, and upper gastrointestinal disorders. ${ }^{\text {b} A d j u s t e d ~ f o r ~ a g e, ~ c a l e n d a r ~}$ year, alcohol consumption, body mass index, hysterectomy, and upper gastrointestinal disorders.

in gastric tumours with a noncardia location, while no association was observed for oesophageal adenocarcinoma.

The low exposure prevalence of HRT and the low incidence of oesophageal and gastric adenocarcinoma in females might explain the lack of previous studies of this topic. Our large sample size was necessary to provide informative results. The reported incidence of adenocarcinoma of the oesophagus and gastric cardia in the UK is higher than that of any other country worldwide (Berrino et al, 1999). Still, the limited number of exposed affected women in our study prohibited extensive subgroup analyses, including the influence of duration of HRT or HRT regimen. The prospective exposure assessment, that is, before cancer occurrence, is the main strength of the study. Also, our manual review of all case patients should reduce misclassification of cancer, although a number of missing values remained on specific histology and subsite. The risk of tumour misclassification was highest for gastric cardia adenocarcinoma, so our estimates for this site are more prone to such error. The lack of a strong inverse association between HRT and oesophageal cancers in our study provides some reassurance that selection bias does not explain the inverse association with gastric cancer. Any remaining tumour misclassification should not be associated with HRT use and could therefore, at the most, dilute our results toward null. Several potential confounding factors were considered, but not Helicobacter pylori infection or socioeconomic status. $H$ pylori infection, an established risk factor for gastric noncardia adenocarcinoma (Uemura et al, 2001), has also been reported to be associated with a reduced risk of oesophageal adenocarcinoma, but not of gastric cardia adenocarcinoma (Hansson et al, 1993; Ye et al, 2004). H pylori infection is positively associated with low social class (Boffetta, 1997), which in turn could be associated with reduced HRT use. As we could not adjust for these factors, our results could be distorted by residual confounding. However, our lack of association between HRT and oesophageal squamous-cell carcinoma, well known to be associated with low social class, does not support a major role for confounding by social class.

Few studies of hormonal factors and risk of oesophageal adenocarcinoma have been published. Our lack of a clear effect of HRT on the risk of oesophageal cancer is in contrast to a study which found that use of HRT, oral contraceptives, and age at menopause were all inversely related with the risk of oesophageal squamous-cell carcinoma (Gallus et al, 2001). The small sample size, the lack of data regarding oesophageal adenocarcinoma, and the retrospective exposure assessment in this study might explain the differences from our study. In line with our current findings is the lack of association between oestrogen treatment and oesophageal adenocarcinoma in our cohort study of prostate cancer patients (Lagergren and Nyren, 1998). There have been somewhat more studies of hormonal influences on gastric cancer. Our findings accord with the age-group-specific male-to-female ratio unique for gastric adenocarcinomas (Sipponen and Correa, 2002). In line with our findings is the decreased risk of gastric adenocarcinoma in our cohort of oestrogen-exposed prostate cancer patients (Lindblad et al, 2004) and a protective trend by HRT on gastric cancer (La Vecchia et al, 1994; Fernandez et al, 2003). However, results from studies of menstrual, reproductive factors, and parity and risk of gastric cancer are partly conflicting (Miller et al, 1980; Plesko et al, 1985; La Vecchia et al, 1994; Palli et al, 1994; Heuch and Kvale, 2000; Inoue et al, 2002; Kaneko et al, 2003). A longer period of fertility among females, that is, the time from menarche to menopause, increases the lifetime exposure to endogenous oestrogens and has been suggestive of a reduced gastric cancer risk (La Vecchia et al, 1994; Palli et al, 1994; Inoue et al, 2002; Kaneko et al, 2003), although a lack of such association, and an inverse association with age at menarche has also been reported (Heuch and Kvale, 2000). Multiparity has been associated with both an increased risk of gastric cancer in several studies (Plesko et al, 1985; La Vecchia et al, 1994; Palli et al, 1994; Heuch and Kvale, 2000; Inoue et al, 2002), and a reduced risk of gastric cancer (Kaneko et al, 2003). Experimental data in rats (Furukawa et al, 1982; Campbell-Thompson et al, 1999) suggest that oestrogen may prevent gastric cancer development.

The inverse association of HRT was particularly strong for gastric noncardia adenocarcinoma. It is not surprising that the associations between HRT and subsites of adenocarcinoma of the oesophagus, gastric cardia, and gastric noncardia differ. Marked differences in risk factor profiles exist between these tumour sites (Fuchs and Mayer, 1995; Enzinger and Mayer, 2003). The evidence of hormonal influence is strongest for gastric noncardia adenocarcinoma. The seemingly stronger protective effect of HRT among older women, who are more likely to have longer exposures, might suggest that a longer dose-response relation exists. This, however, could not be confirmed though our numbers were limited. 
The mechanism of a potential protective effect of HRT on gastric cancer is unknown. Oestrogen receptors have been identified in normal and cancer tissue of the oesophagus and stomach (Korenaga et al, 1998; Akgun et al, 2002; Matsuyama et al, 2002). Oestrogens may prevent colon cancer by decreasing bile acid concentration or by direct effects on the colonic mucosa, as suggested by in vitro studies (McMichael and Potter, 1980; Nanda et al, 1999), and this may also apply in gastric adenocarcinoma. The fact that the protective effect of HRT is stronger for noncardia tumours, that is, those closer to the bile duct, might support this possibility. Women have a lower gastric acid secretion than men, and oestrogen reduces acid gastric secretion and the mass of parietal cells in rats (Adeniyi, 1991), so oestrogen may affect gastric acid production.

The relation between HRT and gastric adenocarcinoma warrants further research before any clinical implications would be appropriate, particularly given the initial enthusiasm about the seemingly protective effect of HRT against cardiovascular disease, which was later not supported (Nelson et al, 2002).

In conclusion, our large study using a prospective database indicates that HRT is associated with a risk reduction of gastric

\section{REFERENCES}

Adeniyi K (1991) Gastric acid secretion and parietal cell mass: effect of sex hormones. Gastroenterology 101: 66-69

Akgun H, Lechago J, Younes M (2002) Estrogen receptor-beta is expressed in Barrett's metaplasia and associated adenocarcinoma of the esophagus. Anticancer Res 22: 1459-1461

Berrino F, Esteve J, Gatta G, Hakulinen T, Micheli A, Sant M, Verdecchia A (1999) Survival of Cancer Patients in Europe: The Eurocare-2 study, Vol. IARC Scientific Publications No. 151. Lyon: International Agency for Research on Cancer

Boffetta P (1997) Infection with Helicobacter pylori and parasites, social class and cancer. IARC Sci Publ 138: 325-329

Campbell-Thompson M, Lauwers GY, Reyher KK, Cromwell J, Shiverick KT (1999) 17Beta-estradiol modulates gastroduodenal preneoplastic alterations in rats exposed to the carcinogen $N$-methyl- $N^{\prime}$-nitro-nitrosoguanidine. Endocrinology 140: 4886-4894

Corley DA, Buffler PA (2001) Oesophageal and gastric cardia adenocarcinomas: analysis of regional variation using the cancer incidence in five continents database. Int J Epidemiol 30: 1415-1425

Crew KD, Neugut AI (2004) Epidemiology of upper gastrointestinal malignancies. Semin Oncol 31: 450-464

Enzinger PC, Mayer RJ (2003) Esophageal cancer. N Engl J Med 349: 2241

EUROGAST (1993) Epidemiology of, and risk factors for, Helicobacter pylori infection among 3194 asymptomatic subjects in 17 populations. The EUROGAST Study Group. Gut 34: $1672-1676$

Fernandez E, Gallus S, Bosetti C, Franceschi S, Negri E, La Vecchia C (2003) Hormone replacement therapy and cancer risk: a systematic analysis from a network of case-control studies. Int J Cancer 105: $408-412$

Fuchs CS, Mayer RJ (1995) Gastric carcinoma. N Engl J Med 333: $32-41$

Furukawa H, Iwanaga T, Koyama H, Taniguchi H (1982) Effect of sex hormones on carcinogenesis in the stomachs of rats. Cancer Res 42: $5181-5182$

Gallus S, Bosetti C, Franceschi S, Levi F, Simonato L, Negri E, La Vecchia C (2001) Oesophageal cancer in women: tobacco, alcohol, nutritional and hormonal factors. Br J Cancer 85: $341-345$

Gammon MD, Schoenberg JB, Ahsan H, Risch HA, Vaughan TL, Chow WH, Rotterdam H, West AB, Dubrow R, Stanford JL, Mayne ST, Farrow DC, Niwa S, Blot WJ, Fraumeni Jr JF (1997) Tobacco, alcohol, and socioeconomic status and adenocarcinomas of the esophagus and gastric cardia. J Natl Cancer Inst 89: 1277 - 1284

Garcia Rodriguez LA, Perez Gutthann S (1998) Use of the UK general practice research database for pharmacoepidemiology. $\mathrm{Br} \mathrm{J}$ Clin Pharmacol 45: 419-425

Hansson LE, Engstrand L, Nyren O, Evans Jr DJ, Lindgren A, Bergstrom R, Andersson B, Athlin L, Bendtsen O, Tracz P (1993) Helicobacter pylori adenocarcinoma, particularly of the noncardia site, while no association was found for oesophageal adenocarcinoma. As we could not control for $H$. pylori infection or social class, our findings must be regarded as tentative. If oestrogens truly and strongly protect against the development of gastric adenocarcinoma, its male predominance may be partly explained by the endogenous oestrogen exposure during women's fertile years. Further research on the potential benefits and harm of sex hormones in relation to gastric cancer may be warranted.

\section{ACKNOWLEDGEMENTS}

We are indebted to all collaborators at the GPRD for all their support. This study was financially supported by Astra Zeneca R\&D, Sweden, by the Swedish Cancer Society, and by the Swedish Research Council; these bodies did not have any influence on study design or conduct of the study, or collection, management, analysis, or interpretation of data, and did not participate in preparation, review, or approval of the manuscript. infection: independent risk indicator of gastric adenocarcinoma. Gastroenterology 105: 1098-1103

Heuch I, Kvale G (2000) Menstrual and reproductive factors and risk of gastric cancer: a Norwegian cohort study. Cancer Causes Control 11: $869-874$

Moller H, Heseltine E, Vainio H (1994) Infection with Helicobacter pylori. In Shistosomes, Liver Flukes and Helicobacter pylori. Lyon: IARC

Inoue M, Ito LS, Tajima K, Yamamura Y, Kodera Y, Takezaki T, Hamajima N, Hirose K, Kuroishi T, Tominaga S (2002) Height, weight, menstrual and reproductive factors and risk of gastric cancer among Japanese postmenopausal women: analysis by subsite and histologic subtype. Int $J$ Cancer 97: $833-838$

Jick H, Jick SS, Derby LE (1991) Validation of information recorded on general practitioner based computerised data resource in the United Kingdom. BMJ 302: $766-768$

Jick SS, Kaye JA, Vasilakis-Scaramozza C, Garcia Rodriguez LA, Ruigomez A, Meier CR, Schlienger RG, Black C, Jick H (2003) Validity of the general practice research database. Pharmacotherapy 23: $686-689$

Kaneko S, Tamakoshi A, Ohno Y, Mizoue T, Yoshimura T (2003) Menstrual and reproductive factors and the mortality risk of gastric cancer in Japanese menopausal females. Cancer Causes Control 14: $53-59$

Kelley JR, Duggan JM (2003) Gastric cancer epidemiology and risk factors. $J$ Clin Epidemiol 56: 1 -9

Korenaga D, Orita H, Okuyama T, Kinoshita J, Maekawa S, Ikeda T, Sugimachi K (1998) Sex hormone-receptor-negative tumors have a higher proliferative activity than sex hormone-receptor-positive tumors in human adenocarcinomas of the gastrointestinal tract. Surg Today 28: $1007-1014$

Lagergren J, Bergstrom R, Lindgren A, Nyren O (1999a) Symptomatic gastroesophageal reflux as a risk factor for esophageal adenocarcinoma. N Engl J Med 340: 825-831

Lagergren J, Bergstrom R, Lindgren A, Nyren O (2000) The role of tobacco, snuff and alcohol use in the aetiology of cancer of the oesophagus and gastric cardia. Int J Cancer 85: $340-346$

Lagergren J, Bergstrom R, Nyren O (1999b) Association between body mass and adenocarcinoma of the esophagus and gastric cardia. Ann Intern Med 130: $883-890$

Lagergren J, Nyren O (1998) Do sex hormones play a role in the etiology of esophageal adenocarcinoma? A new hypothesis tested in a populationbased cohort of prostate cancer patients. Cancer Epidemiol Biomarkers Prev 7: 913-915

La Vecchia C, D’Avanzo B, Franceschi S, Negri E, Parazzini F, Decarli A (1994) Menstrual and reproductive factors and gastric-cancer risk in women. Int J Cancer 59: $761-764$ 
Lindblad M, Lagergren J, Garcia Rodriguez LA (2005) Nonsteroidal antiinflammatory drugs and risk of esophageal and gastric cancer. Cancer Epidemiol Biomarkers Prev 14: 444-450

Lindblad M, Ye W, Rubio C, Lagergren J (2004) Estrogen and risk of gastric cancer: a protective effect in a nationwide cohort study of patients with prostate cancer in Sweden. Cancer Epidemiol Biomarkers Prev 13: $2203-2207$

Matsuyama S, Ohkura Y, Eguchi H, Kobayashi Y, Akagi K, Uchida K, Nakachi K, Gustafsson JA, Hayashi S (2002) Estrogen receptor beta is expressed in human stomach adenocarcinoma. J Cancer Res Clin Oncol 128: $319-324$

McMichael AJ, Potter JD (1980) Reproduction, endogenous and exogenous sex hormones, and colon cancer: a review and hypothesis. J Natl Cancer Inst 65: $1201-1207$

Miller AB, Barclay TH, Choi NW, Grace MG, Wall C, Plante M, Howe GR, Cinader B, Davis FG (1980) A study of cancer, parity and age at first pregnancy. J Chronic Dis 33: 595-605

Muir CS, McKinney PA (1992) Cancer of the oesophagus: a global overview. Eur J Cancer Prev 1: 259-264

Nanda K, Bastian LA, Hasselblad V, Simel DL (1999) Hormone replacement therapy and the risk of colorectal cancer: a meta-analysis. Obstet Gynecol 93: $880-888$
Nelson HD, Humphrey LL, Nygren P, Teutsch SM, Allan JD (2002) Postmenopausal hormone replacement therapy: scientific review. JAMA 288: $872-881$

Palli D, Cipriani F, Decarli A, Galli M, Saieva C, Fraumeni Jr JF, Blot WJ, Buiatti E (1994) Reproductive history and gastric cancer among postmenopausal women. Int J Cancer 56: $812-815$

Parkin DM (2001) Global cancer statistics in the year 2000. Lancet Oncol 2: $533-543$

Plesko I, Preston-Martin S, Day NE, Tzonou A, Dimitrova E, Somogyi J (1985) Parity and cancer risk in Slovakia. Int J Cancer 36: 529-533

Sipponen P, Correa P (2002) Delayed rise in incidence of gastric cancer in females results in unique sex ratio (M/F) pattern: etiologic hypothesis. Gastric Cancer 5: 213-219

Uemura N, Okamoto S, Yamamoto S, Matsumura N, Yamaguchi S, Yamakido M, Taniyama K, Sasaki N, Schlemper RJ (2001) Helicobacter pylori infection and the development of gastric cancer. N Engl J Med 345: $784-789$

Ye W, Held M, Lagergren J, Engstrand L, Blot WJ, McLaughlin JK, Nyren O (2004) Helicobacter pylori infection and gastric atrophy: risk of adenocarcinoma and squamous-cell carcinoma of the esophagus and adenocarcinoma of the gastric cardia. J Natl Cancer Inst 96: $388-396$ 